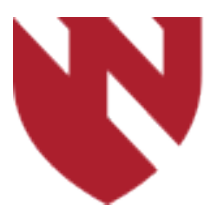

September 2020

\title{
Neuroinvasive West Nile Virus: A Case Series in Nebraska
}

\author{
Matthew V. Purbaugh \\ University of Nebraska Medical Center \\ Erin Smith \\ University of Nebraska Medical Center \\ T. Scott Diesing \\ University of Nebraska Medical Center \\ Sachin Kedar \\ University of Nebraska Medical Center
}

Tell us how you used this information in this short survey.

Follow this and additional works at: https://digitalcommons.unmc.edu/gmerj

Part of the Higher Education Commons, and the Medicine and Health Sciences Commons

\section{Recommended Citation}

Purbaugh, M. V., Smith, E., Diesing, T., , Kedar, S. Neuroinvasive West Nile Virus: A Case Series in Nebraska. Graduate Medical Education Research Journal. 2020 Sep 29; 2(1).

https://digitalcommons.unmc.edu/gmerj/vol2/iss1/75

This Conference Proceeding is brought to you for free and open access by DigitalCommons@UNMC. It has been accepted for inclusion in Graduate Medical Education Research Journal by an authorized editor of DigitalCommons@UNMC.For more information, please contact digitalcommons@unmc.edu. 
Neuroinvasive West Nile Virus: A Case Series in Nebraska

Creative Commons License

(c) $\odot \Theta \Theta$

This work is licensed under a Creative Commons Attribution-Noncommercial-No Derivative Works 4.0 License. 
SDS is associated with an increased risk of developing myelodysplastic syndrome (MDS) and leukemia. Hematopoietic stem cell transplantation (HSCT) is the only curative treatment of bone marrow dysfunction in SDS. Indications for transplant include severe cytopenias, MDS, and leukemia.

Methods: Bone Marrow Biopsy, Transplant. Consent was obtained to use this case for educational purposes.

Results: A 2 month-old male presented with pallor, diarrhea and anemia. He subsequently developed thrombocytopenia and neutropenia. A bone marrow biopsy was performed and demonstrated hypocellular bone marrow. Parents reported a history of oily stools and lab findings were suggestive of pancreatic insufficiency. The patient had an inconclusive genetic work-up but was clinically diagnosed with SDS. The patient was weekly transfusions at 4 yearsold. Due to his transfusion dependence, he was determined to be a candidate for HSCT. The patient received a novel reduced intensity conditioning followed by an allogeneic mismatched unrelated bone marrow transplant. Complications following transplant included mucositis, moderate veno-occlusive disease, and disseminated adenovirus. He is now 6 years-old, fully engrafted, off immunosuppression, and transfusion-independent.

Conclusion: Our patient is the first in Nebraska with SDS to receive a successful HSCT. Early recognition and diagnosis of the disease can decrease the incidence of MDS/ AML and transfusion-related complications. In SDS patients who progress to transplant, reduced intensity conditioning can decrease transplant-related morbidity and mortality and improve long-term quality of life.

https://doi.org/10.32873/unmc.dc.gmerj.2.1.070

\section{Acute Onset Parkinson's Disease Secondary to West Nile Virus Encephalitis Matthew Purbaugh ${ }^{1}$, Fuad-al Ali ${ }^{1}$, T. Scott Diesing ${ }^{1}$, Amy Hellman $^{1}$}

${ }^{1}$ University of Nebraska Medical Center, Department of Neurological Sciences

\section{Mentor: Amy Hellman}

Program: Neurological Sciences

Type: Case Report

Background: Acute onset Parkinsonism has a variety of causes including dopamine antagonists, strokes and viral causes including flaviviruses such as WNV, St. Louis encephalitis and Japanese encephalitis, and influenza.

Methods: History, physical exam, laboratory studies and MRI.

Results: A healthy, well-functioning 79-yearold male with PMH of MCI presented with right sided tremor, fever, encephalopathy and meningismus, with no previous history of movement disorders. Physical exam revealed bilateral upper extremity cog-wheel rigidity, narrow-based gait with decreased arm swing, 4-step turn, prominent right-sided resting tremor, facial tremor, bradykinesia with decrement on finger tapping and myoclonus. MRI showed white matter disease consistent with chronic small vessel disease. CSF showed pleocytosis with monocyte predominance, elevated protein and WNV IgM indicating an acute infection. The Parkinsonism started to show improvement and five months later he reported continued improvement in his tremor with a minor residual postural tremor, resolution of the myoclonus and improvement in his gait. He continued to have difficulty functioning at his prior level due to bradykinesia and worsening of his preexisting MCI.

Conclusion: Viral induced Parkinsonism has been previously ascribed to a variety of viruses including WNV. ${ }^{1,2,3}$ One case in 2003 described two relatively healthy patients who developed an acute encephalitis and concurrent parkinsonism that resolved with resolution of the disease. ${ }^{2}$ While a rare cause of Parkinsonism, WNV should be suspected in cases of acute onset Parkinson's disease (PD) that occurs during or after a febrile illness. Further investigation is required to determine the incidence, predisposing factors and the likelihood of developing idiopathic PD.

https://doi.org/10.32873/unmc.dc.gmerj.2.1.090

\section{References}

1 Jang H, Boltz DA, Webster RG, Smeyne RJ. (2009). Viral parkinsonism. Biochim Biophys Acta. 1792(7):714-21.

2 Robinson RL, Shahida S, Madan N, Rao S, Khardori N. (2003). Transient parkinsonism in West Nile virus encephalitis. American Journal of Medicine 15(3):252-3

3 Solomon T, Fisher AF, Beasley DWC, Mandava P, Granwehr BP, Langsjoen H, Tracassos RD, Barrett, ADT, Resh, RB. (2003). Natural and Nosocomial Infection in a patient with West Nile Encephalitis and Extrapyramidal Movement Disorders. Clinical Infectious Disease 36:e140-5.

\section{Neuroinvasive West Nile Virus: A Case Series in Nebraska Matthew Purbaugh ${ }^{1}$, Erin Smith ${ }^{1}$, T. Scott Diesing ${ }^{1}$, Sachin Kedar ${ }^{1}$}

${ }^{1}$ University of Nebraska Medical Center, Department of Neurological Sciences

\section{Mentor: Sachin Kedar}

Program: Neurological Sciences

Type: Case Report

Background: Between May and October 2018, there were 110 reported cases of neuroinvasive West Nile Virus (WNV) in Nebraska. The arbovirus can have many CNS manifestations including meningoencephalitis, poliomyelitis like syndrome, and movement disorders. We present four unusual presentations of neuroinvasive WNV seen during the summer of 2018.
Methods: We reviewed charts of four patients admitted to neurology service who had positive serology and/or polymerase chain reaction (PCR) testing for $\mathrm{WNV}$.

Results: Case 1: A 39-year-old female with diffuse large B-cell lymphoma presented with fever, encephalopathy, and flaccid paraplegia. MRI showed T2 hyperintensities involving the bilateral thalami, temporal lobes, midbrain, pons, and spinal cord which were suspicious for CNS lymphoma. WNV was confirmed by PCR as her prior treatment with RCHOP made her serum and CSF serology falsely negative. Case 2: A 49-year-old female presented with left sided ptosis and left arm weakness. WNV was confirmed by CSF lymphocytic pleocytosis and positive WNV IgM. Case 3: A 79-year old male presented with acute onset parkinsonism with positive CSF WNV IgM. Case 4: A 31 year-old male who presented with uveomeningitis syndrome with uveitis of the right eye, fever, headache, nuchal rigidity and CSF pleocytosis. An autoimmune cause was suspected until CSF showed WNV IgM. All four patients showed varying amounts of neurological recovery with supportive care. 
Conclusion: The diverse presentations of neuroinvasive WNV present diagnostic challenges. Frequent alerts from the Nebraska DHHS prompted deliberate searches for WNV. A high clinical suspicion for neuroinvasive WNV in endemic areas can prevent delays in diagnosis and appropriate care.

https://doi.org/10.32873/unmc.dc.gmerj.2.1.089

\section{Lingual Nerve Anesthesia: A Rare Atypical Presentation of a Vestibular Schwannoma \\ Blair Racker ${ }^{1}$, Tyler J. Holley ${ }^{1}$, Lei Yu², Jason Untrauer ${ }^{1}$}

${ }^{1}$ University of Nebraska Medical Center, Department of Surgery, Division of Oral \& Maxillofacial Surgery

${ }^{2}$ University of Nebraska Medical Center, Department of Radiology

Mentor: Jason Untrauer

Program: Surgery, Division of Oral \& Maxillofacial Surgery

Type: Case Report

Background: Vestibular schwannomas (VS) are benign, slow-growing tumors that develop from the vestibular nerve. They classically present with hearing loss and tinnitus. Reported incidence of atypical presentations of VS range from 3.7-10.7\%.1-2 Rarely, VS can impinge on the trigeminal nerve, and result in facial pain or numbness.3-4 We present an unusual case of VS presenting with isolated anesthesia of the lingual nerve, a branch of the trigeminal nerve.
Methods: A 43-year-old otherwise healthy female was evaluated for new onset numbness of her left tongue that started a few days after a dental cleaning. She denied loss taste. Review of systems was negative otherwise. Examination revealed atrophy of filiform papillae of the left tongue and loss of sensation to both painful stimulus and light touch. Her examination was otherwise normal. A brain magnetic resonance imaging (MRI) was performed to evaluate for both intracranial pathology and extra-cranial lingual nerve pathology.

MRI demonstrated a left cerebellopontine angle mass (maximum diameter, $2.1 \mathrm{~cm}$ ) with signals characteristic of a schwannoma. The mass was noted to be vestibular in origin with impingement on both the trigeminal and facial cranial nerves. Her symptoms ultimately progressed with loss of sensation of her left lower lip, cheek and forehead. She also reported late symptoms dryness of her left eye.

Results: The patient underwent transcranial tumor resection with confirmation of schwannoma upon histopathologic analysis. The surgery resulted in immediate resolution of her trigeminal nerve anesthesia

Conclusion: Vestibular schwannomas can atypically present as isolated lingual nerve paresthesia. In turn, patients who present with lingual nerve anesthesia without a preceding surgical insult should be considered for brain MRI.

https://doi.org/10.32873/unmc.dc.gmerj.2.1.073

\section{Effect of an External Urinary Collection Device on Catheter Associated Urinary Tract Infections in Hospitalized Women \\ Lindsey Rearigh¹, Gayle Gillett ${ }^{2}$, Adrienne Sy², Terry Micheels ${ }^{2}$, Luana Evans², Kelly Goetschkes², Trevor Van Schooneveld ${ }^{1}$, Elizabeth Lyden ${ }^{1}$, Mark Rupp 1 \\ ${ }^{1}$ University of Nebraska Medical Center, Department of Internal Medicine, Division of Infectious Disease ${ }^{2}$ Nebraska Medicine}

Mentor: Mark Rupp

Program: Internal Medicine, Division of Infectious Disease

Type: Original Research

Background: Catheter-associated urinary tract infections (CAUTIs) are a common hospital acquired infection (HAI) resulting in excess morbidity, mortality, and cost. A female external urine collection device (EUCD) was implemented in our facility in efforts to decrease catheter days and limit CAUTI.

Methods: Retrospective, 32 month, quasiexperimental, pre:post study comparing 14 months before and after EUCD introduction with a three month introduction period.
Results: The overall CAUTI rate per 1000 patient days (PD) decreased slightly from 0.24 to $0.20(\mathrm{P}=0.44$; model risk $0.86(95 \%$ CI 0.58-1.26), while the rate per 1000 catheter days $(\mathrm{CD})$ increased slightly 1.5 to $1.6(\mathrm{P}=0.76$; model risk $1.06(95 \%$ CI 0.73 1.56). The CAUTI rate for men increased from 0.09 to $0.11(\mathrm{P}=0.42)$ and from 0.99 to $1.55(\mathrm{P}=0.17)$; per $1000 \mathrm{PD}$ and $1000 \mathrm{CD}$, with a model predicted risk of 1.29 and 1.56 respectively. For women, the rate of CAUTI decreased from 0.15 to $0.09(\mathrm{P}=0.10)$ and from 2.12 to $1.65(\mathrm{P}=0.38)$ per $1000 \mathrm{PD}$ and $1000 \mathrm{CD}$, with a model predicted risk of 0.61 and 0.38 respectively. A significant $(\mathrm{P}<0.0001)$ decrease in catheter days $(\mathrm{CD}$ per $1000 \mathrm{PD})$ was observed for all hospitalized patients (158.56 to 128.3$)$; men (87.06 to 72.15 ); women (71.49 to 56.15$)$ with model predicted risk of $0.81,0.83$, and 0.79 respectively.

Conclusion: Introduction of an EUCD for women was associated with a significantly decreased indwelling catheter usage and a trend $(\mathrm{P}=0.10)$ toward decreased CAUTI's per $1000 \mathrm{pt} \mathrm{d}$ for women. Additional studies on EUCD association with UTI (both CAUTI and non-catheter UTI) are warranted.

https://doi.org/10.32873/unmc.dc.gmerj.2.1.075 